\title{
Cooperation During Orthodontic Treatment of Patients with I Phase and Phase Orthodontic Treatment
}

\author{
Cooperación Durante el Tratamiento Ortodóntico de Pacientes \\ Tratados Previamente con Ortodoncia Interceptiva
}

\author{
Sandra Rojas; Juan Manuel Cárdenas; Angela Sierra \& Diego Rojas
}

ROJAS, S; CÁRDENAS, J. M.; SIERRA, A. \& ROJAS, D. Cooperation during orthodontic treatment of patients with I phase and II phase orthodontic treatment. Int. J. Odontostomat., 15(2):526-531, 2021.

ABSTRACT: To evaluate differences in cooperation of adolescent patients in active orthodontic treatment between those who received one phased treatment (no prior interceptive or early treatment) and two phased treatment (prior interceptive or early treatment and subsequent corrective treatment). A prospective cohort study was carried out in 132 patients undergoing orthodontic treatment between 10 and 17 years old at CES University Dental Clinics and in 9 private practices in Medellín Colombia; two groups of 66 patients were defined; one that received two phased treatment and one that received one phased treatment. The Orthodontic Patient Cooperation Scale (OPCS) was applied to all individuals every three months during the first year of treatment in order to assess cooperation. Statistical differences between both groups were assessed using the SSPS $®$ software program. Significantly greater cooperation $(\mathrm{M}=4.6)$ was observed in patients who had received two phased treatment compared with those who were only subjected to one phased treatment $(M=2.3)$. Patient cooperation during orthodontic treatment does not seem to be affected by two phased treatment and to the contrary seems to have a positive impact when comparing it with individuals with one phased treatment. The most important factors found to influence cooperation were correlated with attitude, interest and commitment to treatment, patient and parental motivation. The OPCS scale proved to be useful for evaluating cooperation and making comparisons with other studies.

KEY WORDS: Non-cooperative patients, interceptive orthodontics, OPCS, malocclusion.

\section{INTRODUCTION}

The success of conventional orthodontic treatment depends on various biological, biomechanical and psychosocial factors (Albino et al., 2000; Bos et al., 2005). Different studies have evaluated the influence of patient cooperation and have concluded that it is an important factor that can affect treatment outcome (Daniels et al., 2009; Carvajal \& Sierra, 2013).

Albino (Albino et al., 2000) as well as Sinha \& Nanda (2000) reported that adequate patient cooperation ranges between $40 \%-60 \%$ and is influenced by different aspects such as patient and parental motivation, compliance, adequate use of appliances, and treatment length (Albino et al.; Sinha
\& Nanda). Regarding the latter, it has been suggested that longer treatment periods could be associated with a decrease in cooperation (Mavreas \& Athanasiou, 2008; Abu Alhaija et al., 2010). However, said reports refer to the duration of conventional orthodontic treatment and not to previous interceptive orthodontic treatment or two-phase treatments. In contrast, Gross et al. (1985) reported that patients who initiated with interceptive treatment presented high levels of cooperation initially, but decreased between 20 and $90 \%$ during the corrective phase. Other authors such (Slakter et al., 1980) found that cooperation prolonged treatment times; moreover, Skidmore et al. (2006) reported early treatment termination or suspension due to lack of commitment, motivation and cooperation. 
Although a significant percentage of patients undergoing two phased treatment, and it could be inferred that increased treatment times could affect cooperation during corrective treatment, there are no reports in the literature that have evaluated its impact. The purpose of this study was to therefore to evaluate differences in cooperation between patients who received two phased treatment and those who only one received one phased treatment.

\section{MATERIAL AND METHOD}

Design. A non-probabilistic sample of 132 patients between 10 and 17 years old requiring orthodontic treatment who consulted between 2014 and 2015 at CES University Dental Clinics and 9 private practices in Medellin, Colombia was selected; the sample was divided in two groups of 66; an exposed group consistent of patients who had received two phased treatment, and a non-exposed group that included patients who initiated one phased treatment. Patients who failed three or more consecutive appointments during treatment were excluded.
Patient cooperation was assessed with the Orthodontic Patient Cooperation Scale (OPCS) (Table I) designed by Slakter et al. which measures cooperation through patient attitude and compliance (Amado et al., 2008), consisting of a 10 item Likert type scale to be completed by the orthodontist, during the first year of treatment at 3,6, 9 and 12 months.

Calculation of the sample size was made with a $95 \%$ confidence level, $80 \%$ power, a risk of noncooperation of the unexposed group (patients who receive one phased treatment) of $25 \%$ a risk of noncooperation of the exposed group (patients who received two phased treatment) of $50 \%$.

The study design was previously approved by the CES University Institutional Ethics committee and was in compliance with Colombian Legal resolution 008430 that typifies ethical regulations for the performance of clinical human studies.

Statistical analysis. The psychometric properties of the OPCS were verified by means of the Rasch model, in order to perform data analysis (Rojas et al., 2019). A univariate analysis was carried out using

Table I. Scale used for scoring cooperation in adolescent orthodontic patients.

\section{Orthodontic Patient Cooperation Scale}

Jease read the following list of behaviors, keeping in mind the patient named on the cover sheet accompanying this questionnaire. For each item, decide to what extent the statement describes the patient's behavior. Then circle the 'esponse that most closely reflects your estimate of the patient's behavior.

1. This patient keeps appointments and is prompt.

Always Frequently Sometimes Rarely Never

2. This patient has distorted wires and/or loose bands.

Always Frequently Sometimes Rarely Never

3. The parent(s) of this patient is (are) observed to be interested and involved in treatment.

Always Frequently Sometimes Rarely Never

7. This patient speaks of family problems or a poor relationship with parent(s) or demonstrates such problems in nteractions with parent(s), which I have observed.

Always Frequently Sometimes Rarely Never

j. This patient acts enthusiastic and interested in treatment.

Always Frequently Sometimes Rarely Never

j. This patient's behavior is sullen, hostile, belligerent, or rude.

Always Frequently Sometimes Rarely Never

7. This patient cooperates in the use of headgear and/or elastics.

Always Frequently Sometimes Rarely Never

3. This patient complains about treatment procedures.

Always Frequently Sometimes Rarely Never

7. This patient demonstrates excellent oral hygiene.

Always Frequently Sometimes Rarely Never

10. This patient complains about having to wear braces.

Always Frequently Sometimes Rarely Never 
the Stata $v 12.1 \AA$ program (College station, Texas), considering central tendency measures, and dispersion according to the category of the variables. For the bivariate analysis, a comparison was made between the variables of exposure, outcome and adjustment, with the linear model of repeated measures, determining mean cooperation for each category of the independent variables, with a confidence interval of $95 \%$ and their association through Eta statistic. For the multivariate analysis, a linear regression of repeated measures was performed considering the exposed group as intersubject effect and sex, age, socio-economic level, type of malocclusion as co-variables; intra-subject effect (dependent variable) measures were performed at defined times.

\section{RESULTS}

With regards to the sociodemographic and clinical characteristics of the sample, patients had an average age that ranged between $14-15$ years (SD $=1.55-1.9$ ). Twenty five percent belonged to Status 4 socio-economic level (upper middle-class) and 17
$\%$ to Status 3 socio-economic level (middle-class); approximately $60 \%$ were females (Table II).

Table III presents the estimation of average range of cooperation for each treatment period. Cooperation of individuals with two phased treatment was higher $(M=4.6, D S=6.3)$ than those who only received one phased treatment $(M=2.3, D S=2.7)$, with similar significant differences in each time period.

The associations found between cooperation and the characterizing variables of the sample such as socio-economic level, sex, and malocclusion revealed significant differences depending on the history of treatment; those with two phased treatment revealed an average of cooperation 5.1 - 8.1, while those who received one phased treatment did exhibited an average between 2.4 and 3.4. After the initial evaluation period, increased cooperation was observed for both groups (Fig. 1).

Cooperation was expressed differently for males; those who only received one phased treatment, presented an average ranging between 1 and 3 , while those in the group that had two phased treatment, cooperation ranged between 6 and 9 (Fig. 2).

Table II. Characteristics of Participants with one phased treatment and two phased treatment.

\begin{tabular}{|c|c|c|c|c|c|c|c|}
\hline & \multicolumn{7}{|c|}{ Previous Interceptive Treatment } \\
\hline & & \multicolumn{2}{|c|}{ YES } & \multicolumn{2}{|c|}{ NO } & \multicolumn{2}{|c|}{ TOTAL } \\
\hline & & & $\mathrm{n} \quad(\%)$ & 1 & (\%) & & \\
\hline \multirow[t]{2}{*}{ SEX } & Female & 42 & $(31.8 \%)$ & 39 & $(29.5 \%)$ & 81 & $(61.3 \%)$ \\
\hline & Male & 24 & $(18.2 \%)$ & 27 & $(20.5 \%)$ & 51 & $(38.7 \%)$ \\
\hline \multirow[t]{3}{*}{ SOCIO-ECONOMIC } & 3 & 26 & $(19.7 \%)$ & 22 & $(16.7 \%)$ & 48 & $(36.4 \%)$ \\
\hline & 4 & 22 & $(16.7 \%)$ & 31 & $(23.4 \%)$ & 53 & $(40.1 \%)$ \\
\hline & 5 & 18 & $(13.6 \%)$ & 13 & $(9.8 \%)$ & 31 & $(23.4 \%)$ \\
\hline \multirow[t]{3}{*}{ TYPE OF } & I & 18 & $(13.6 \%)$ & 23 & $(17.4 \%)$ & 41 & $(31 \%)$ \\
\hline & II & 34 & $(25.7 \%)$ & 29 & $(22 \%)$ & 63 & $(47.7 \%)$ \\
\hline & III & 14 & $(10.6 \%)$ & 14 & $(10.6 \%)$ & 28 & $(21.2 \%)$ \\
\hline \multirow[t]{2}{*}{ AGE } & & & *14.29 & & * 15.29 & & *14.8 \\
\hline & & & $\star * 1.99$ & & $* * 1,55$ & & **1.8 \\
\hline
\end{tabular}

Table III. Cooperation of Participants with and without two phased treatment.

\begin{tabular}{llcccc}
\hline TREATMENT & & coop3 & coop6 & coop9 & coop12 \\
\hline One phase & Media & 2.39 & 3.11 & 1.49 & 3.74 \\
& S.D & 2.73 & 3.60 & 3.76 & 3.30 \\
Two phase & Media & 4.68 & 5.48 & 2.90 & 7.92 \\
& S.D. & 6.37 & 6.86 & 7.48 & 6.15 \\
Total & Media & 3.54 & 4.29 & 2.20 & 5.83 \\
& S.D & 5.02 & 5.59 & 5.94 & 5.34 \\
\hline
\end{tabular}




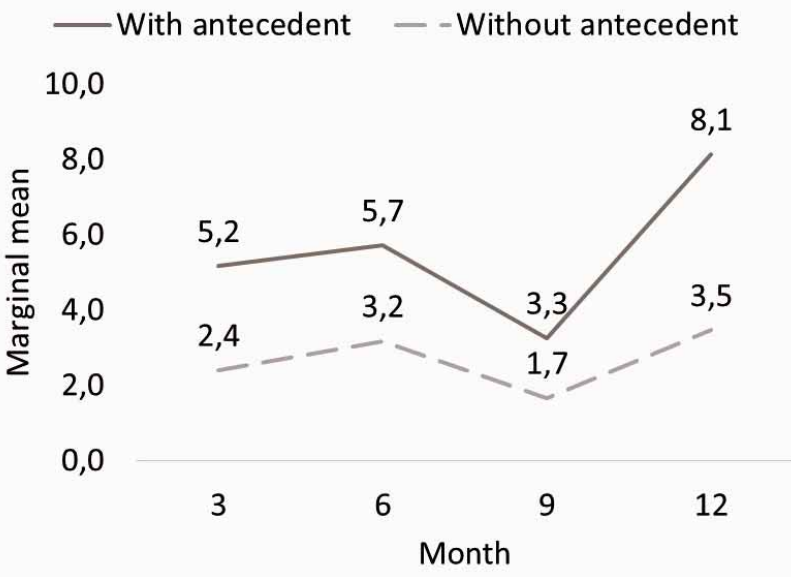

Fig. 1. Adjusted average by model of repeated measures of the degree of cooperation with current treatment based on two phased treatment.
Cooperation according to socioeconomic level was similar with an average ranging between 3 and 9 for both groups, although greater cooperation was evidenced in patients with a two phased treatment (Fig. 3).

Regarding differences in cooperation between malocclusion types, similar values were observed for both groups, except during the final treatment period when increased cooperation was found in those with a two phased treatment. In contrast, individuals with Class III malocclusion exhibited less cooperation overall than those who had one phased treatment (Fig. 4).

\section{-With antecedent \\ - Without antecedent}

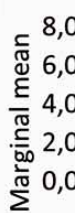

A

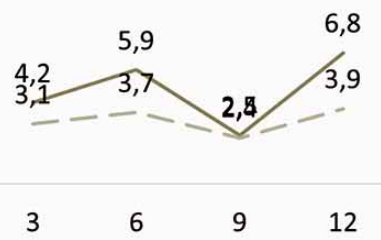
Month

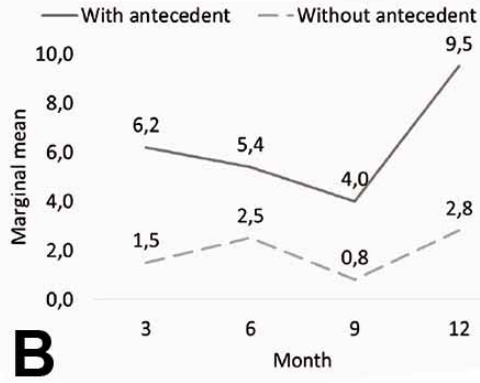

12
Fig. 2 (sections $2 \mathrm{~A}$ and 2B). Average adjusted by model of repeated measures of the degree of cooperation with current treatment, based on two phased treatment by sex of participants.

Section 2A: Females

Section 2B: Males
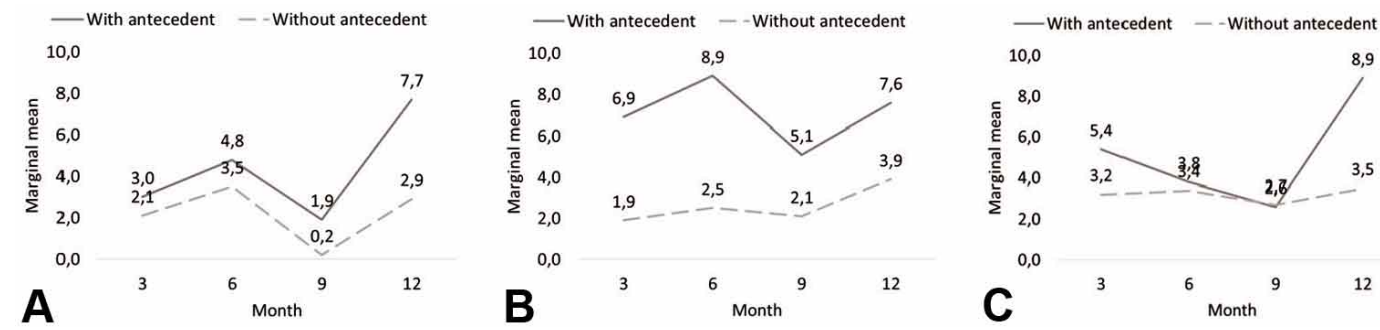

Fig. 3 (sections 3A, 3B and 3C). Average cooperation adjusted by model of repeated measures of the degree of cooperation based on two phased treatment depending on socio-economic level of participants.Section 3A: Middle Socio-economic level. Section 3B: Higher Middle socio-economic level. Section 3C: Upper middle Socio-economic level
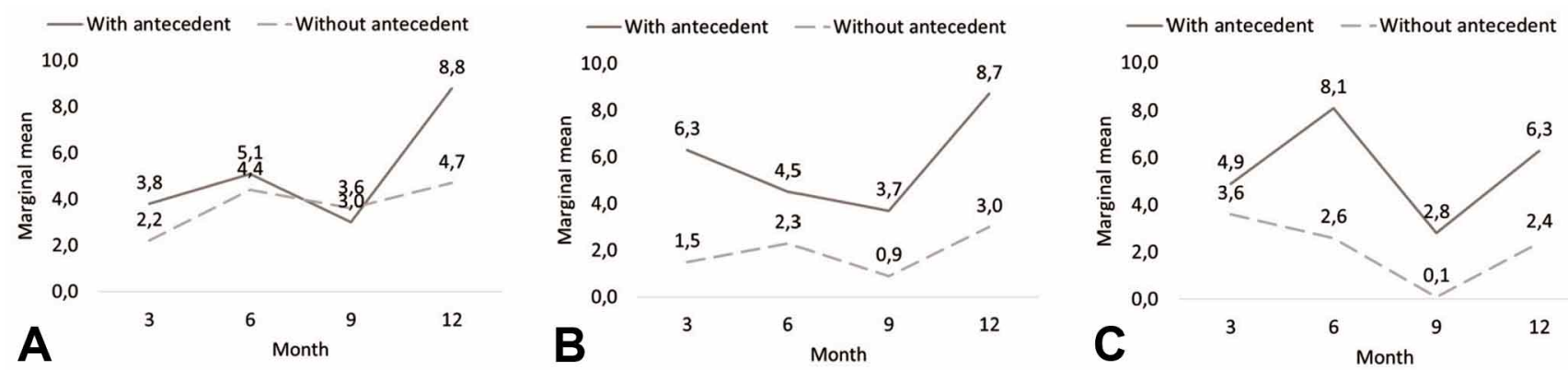

Fig. 4 (sections 4A, 4B and 4C). Average adjusted by model of repeated measures of the degree of cooperation based on two phased treatment depending on type of malocclusion. Section 4A: Class I Malocclusion. Section 4B: Class II Malocclusion. Section 4C: Class III Malocclusion 


\section{DISCUSSION}

The purpose of this study was to assess the effect of one phased treatment and two phased treatment on cooperation. Evaluation of cooperation yielded positive results for both groups; average cooperation of patients with two phased treatment was higher coinciding with Lee et al. (2008) and Hsieh et al. (2005). Results, on the other hand, contrast with those of Carvajal \& Sierra who found cooperation decreased in patients undergoing two phased treatment with a longer duration. The findings of this study could be explained by the fact that in current clinical practice, socio-economic and cultural conditions have influenced patients and their parents to accept two phased treatment (Amado et al.).

Regarding sex, girls from both groups showed an average cooperation that ranged between 3.1 and 6.8 during the first year of treatment, in contrast with boys who presented lower averages in both groups with scores between 1.5 and 6.2, in agreement with Daniels et al. who reported significant differences between boys and girls, and which could be attributed psychosocially to the fact that girls mature earlier, tend to be more aware and self-conscious about their appearance due to social stereotypes (Daniels et al.). This assessment in the case of this study depended on the commitment of participants and their parents taking into account that they outnumbered males (Mtaya et al., 2009). Moreover, a detailed analysis indicated that in both groups, boys and girls who had two phased treatment were more cooperative than their sex counterparts who had not.

The most important factors that influenced cooperation were correlated with those presented in previous studies (Mehra et al., 1998; Hsieh et al.; Tsomos et al., 2014) based on attitude, interest and commitment, motivation, compliance, proper use of appliances, oral hygiene and duration of treatment.

An analysis of treatment periods, indicated differences, that revealed increased cooperation during the first six months, and a decrease after nine months in both groups, possibly due to a perception that no relevant changes in their appearance were observable, to decreased parental supervision, and prolonged treatment times. In contrast, cooperation increased again after 12 months, which could be likely associated to the fact that this is a period when patients begin to observe changes in their appearance.
In summary, the results of this study indicate a higher cooperation rate in patients who received two phased treatment compared to those who did receive one phased treatment, which seems to be associated with patient participation during the interceptive stage, improved communication, motivation and preparation for the corrective stage.

\section{CONCLUSIONS}

- Patients with two phased treatment were statistically more cooperative when compared to patients who only received one phased treatment.

- Differences were evident between sexes, revealing increased cooperation in girls

- The most important factors found to influence cooperation were correlated with attitude, interest and commitment to treatment, patient and parental motivation.

- The OPCS scale proved to be useful for evaluating cooperation and making comparisons with other studies.

\section{ACKNOWLEDGMENTS}

The authors would like to thank the professionals who participated in evaluating the study patients for the development of the research.

ROJAS, S; CÁRDENAS, J. M.; SIERRA, A. \& ROJAS, D. Cooperación durante el tratamiento ortodóntico de pacientes tratados previamente con ortodoncia interceptiva. Int. J. Odontostomat., 15(2):526-531, 2021.

RESUMEN: Evaluar las diferencias en la cooperación de los pacientes adolescentes en el tratamiento de ortodoncia activa entre los que recibieron una fase de tratamiento (sin tratamiento interceptivo previo o temprano) y los que recibieron el tratamiento de dos fases (tratamiento interceptivo previo o temprano y tratamiento correctivo posterior). Se realizó un estudio de cohorte prospectivo en 132 pacientes sometidos a tratamiento de ortodoncia entre $10 \mathrm{y}$ 17 años en la clínica odontológica de la Universidad CES y en 9 consultorios privados en Medellín Colombia; se definieron dos grupos de 66 pacientes; uno que recibió dos fases de tratamiento y otro que recibió una fase de tratamiento. La Escala de Cooperación del Paciente de Ortodoncia (OPCS) se aplicó a todas las personas cada tres meses durante el primer año de tratamiento para evaluar la cooperación. Las diferencias estadísticas entre ambos grupos se 
evaluaron utilizando el programa de software SSPS $®$. Se observó una cooperación significativamente mayor $(\mathrm{M}=4.6)$ en pacientes que habían recibido tratamiento dos fases en comparación con aquellos que solo fueron sometidos a una fase de tratamiento. $(M=2.3)$. La cooperación del paciente durante el tratamiento de ortodoncia no parece verse afectada por el tratamiento en dos fases y, por el contrario, parece tener un impacto positivo cuando se compara con individuos con un tratamiento en una fase. Los factores más importantes que influyeron en la cooperación se correlacionaron con la actitud, el interés y el compromiso con el tratamiento, la motivación del paciente y de los padres. La escala OPCS demostró ser útil para evaluar la cooperación y hacer comparaciones con otros estudios.

PALABRAS CLAVE: Pacientes no cooperativos, ortodoncia interceptiva, OPCS, maloclusión.

\section{REFERENCES}

Abu Alhaija, E. S.; Aldaikki, A.; Al-Omairi, M. K. \& Al-Khateeb, S. $\mathrm{N}$. The relationship between personality traits, pain perception and attitude toward orthodontic treatment. Angle Orthod., 80(6):1141-9, 2010.

Albino, J. E. N. Factors influencing adolescent cooperation inorthodontic treatment. Semin. Orthod., 6(4):214-23, 2000.

Amado, J.; Sierra, A. M.; Gallón, A.; Alvarez, C. \& Baccetti, T. Relationship between personality traits and cooperation of adolescent orthodontic patients. Angle Orthod., 78(4):688-91, 2008.

Bos, A.; Hoogstraten, J. \& Prahl-Andersen, B. Attitudes towards orthodontic treatment: a comparison of treated and untreated subjects. Eur. J. Orthod., 27(2):148-54, 2005.

Carvajal, C. \& Sierra, A. Evaluation of the changes in the cooperation of patients treated in 2 phases of Orthodontic Treatment (Orthopedics and Orthodontics). Thesis. Medellin, Universidad CES, 2013

Daniels, A. S.; Seacat, J. D. \& Inglehart, M. R. Orthodontic treatment motivation and cooperation: a cross-sectional analysis of adolescent patients' and parents' responses. Am. J. Orthod. Dentofacial Orthop., 136(6):780-7, 2009.

Gross, A. M.; Samson, G. \& Dierkes, M. Patient cooperation in treatment with removable appliances: a model of patient noncompliance with treatment implications. Am. J. Orthod., 87(5):392-7, 1985.

Hsieh, T. J.; Pinskaya, Y. \& Roberts, W. E. Assessment of orthodontic treatment outcomes: early treatment versus late treatment. Angle Orthod., 75(2):162-70, 2005.

Lee, S. J.; Ahn, S. J. \& Kim, T. W. Patient compliance and locus of control in orthodontic treatment: a prospective study. Am. J. Orthod. Dentofacial Orthop., 133(3):354-8, 2008.

Mavreas, D. \& Athanasiou, A. E. Factors affecting the duration of orthodontic treatment: a systematic review. Eur. J. Orthod., 30(4):386-95, 2008.

Mehra, T.; Nanda, R. S. \& Sinha, P. K. Orthodontists' assessment and management of patient compliance. Angle Orthod., 68(2):115-22, 1998.

Mtaya, M.; Brudvik, P. \& Astrøm, A. N. Prevalence of malocclusion and its relationship with socio-demographic factors, dental caries, and oral hygiene in 12- to 14-year-old Tanzanian schoolchildren. Eur. J. Orthod., 31(5):467-76, 2009.
Rojas, S.; Cárdenas, J. M.; Sierra, A. \& Rojas-Gualdrón, D. F. Análisis Rasch de la medida de cooperación del paciente ortodóncico en adolescentes de Medellín. CES Psicol., 12(1):4353, 2019.

Sinha, P. K. \& Nanda, R. S. Improving patient compliance inorthodontic practice. Semin. Orthod., 6(4):237-41, 2000.

Skidmore, K. J.; Brook, K. J.; Thomson, W. M. \& Harding, W. J. Factors influencing treatment time in orthodontic patients. $\mathrm{Am}$. J. Orthod. Dentofacial Orthop., 129(2):230-8, 2006.

Slakter, M. J.; Albino, J. E.; Fox, R. N. \& Lewis, E. A. Reliability and stability of the orthodontic Patient Cooperation Scale. Am. J. Orthod., 78(5):559-63, 1980.

Tsomos, G.; Ludwig, B.; Grossen, J.; Pazera, P. \& Gkantidis, N. Objective assessment of patient compliance with removable orthodontic appliances: a cross-sectional cohort study. Angle Orthod., 84(1):56-61, 2014.

Corresponding author:

Sandra Rojas

School of Dentistry

CES University

COLOMBIA

E-mail: odontoforense@gmail.com 